\section{NATURAL SELECTION-MR. WALLACE'S REPLY TO MR. BENNETT}

MR. A. W. BENNETT'S article entitled "The Theory of Natural Selection from a Mathematical Point of View," contairs several criticisms on my own writings, and touches on some points which have not yet been fully discussed. I propose, therefore, to reply to such of these as appear to be of sufficient importance.

The first objection brought forward (and which had been already advanced by the Duke of Argyll) is, that the very title of Mr. Darwin's celebrated work is a misnomer, and that the real "origin of species" is that spon taneous tendency to variation which has not yet been accounted for. Mr. Benne.t further remarks, that throughout my volume of "Essays" I appear to be unconscious that the theory I advocate does not go to the root of the matter; and this unconsciousness is not apparent only, for I maintain, and am prepared to prove, that the theory, if true, does go to the root of the question of the origin of species. The objection, which, from its being so often quoted and now again brought forward, is evidently thought to be an important one, is founded on a misapprehension of the right meaning of words. It ignores the fact that the word "species" denotes something more than "variety" or "individual." A species is an organic form which, for periods of great and indefinite length as compared with the duration of human life, fluctuates only within narrow limits. But the "spontaneous tendency to variation" is a!together antagonistic to such comparative stability, and would, if unchecked, entirely destroy all "species." Abolish, if possible, selection and survival of the fittest, so that every spontaneous variation should survive in equal proportion with all others, and the result must inevicably be an endless variety of unstable forms, no one of which would answer to what we mean by the word "species." No other cause but silecilion, has yet been discovered capable of perpetuating and giving stability to some forms and causing the disappearance of hosts of others, and therefore Mr. Darwin's book, if there is any truth in it at all, has a logical claim to its title. It shows how "species," or stable forms, are produced out of unstable spontineous variations; which is certainly to trace their "origin." The distinction of "species" and "individual" is equally important. A horse or a number of horses, as such, do not constitute a species. It is the comparative permanence of the form as distinguished from the ass, quagga, zebra, tapir, camel, \&c., that makes them one. Were there a mass of intermediate forms connecting all these animals by fine gradations, and hardly a dozen individuals alike-as would probably be the case had selection not acted-there might be a few horses, but there would be no such thing as a species of horse. That could only be produced by some power capable of eliminating intermediate forms as they arise, and preserving all of the true horse type, and such a power was first shown to exist by Mr. Darwin. The origin of varieties and of individuals is one thing, the origin of species another.

Mr. Bennett next discusies the phenomena of "mimicry," and proposes to show, by mathematical calculations, that the effects could not be produced by natural selection. But, at the very outset, he makes an important error, which seriuusly affects his subsequent reasonings; for he leads his readers to understand that there is only one completely mimicking species of Leptalis, while the majority are of the normal white butterfly type. The fact is, however, that but few species of Leptalis retain the simple colouring of their allies the Pieridæ, while the great majority are either coloured like the Heliconidæ, cr show a considerable amount of colour or marking in that direction. He is also apparently unaware that some Heliconidæ (Ithomia eurimedice, for example) approximate in colour to the normal white and yellow species of Loptalis, and thus renders it much less difficult to under- stand how a sufficient amount of variation in colour might occur at a first step, to produce a resemblance which, viewed at some cons derable distance, would be deceptive, and therefore useful.

We next come to the demonstration by means of figures, and we here find still more serious errors. Mr. Bennett says, that supposing a Leptalis may vary in twenty different ways, one only being the direction required,"the chance of any individual producing a descendant which will take its place in the succeeding generation varying in the required direction, is $\frac{1}{20}$; the chance of this operation being repeated in the second generation is $-\frac{I}{20^{2}}=\frac{1}{40} \overline{0}$; the chance of this occurring for ten successive generations is $\frac{\mathrm{I}}{2 \mathrm{O}^{\mathrm{O}} \mathrm{t}}$, or about one in ten billions ;" whence it is concluded that there are overwhelming chances against any progressive variation in the right direction ever taking place. But first, I do not admit the assumption that only one variation out of twenty would be in the right direction; when it is remembered how great is the variety of the Heliconidæ, both in colour and marking. It seems more likely that one-fourth or one-third at least would help to approximate to some of them, and thus be useful. Taking, however, Mr. Bennett's own figures, there are three great oversights in this one short sentence. The first is, that each Leptatis produces, not one only, but perhaps twenty or fifty offspring; the second is, that the right variation has, by the hypothesis, a greater chance of surviving than the rest; and the third, that at each succeeding generation the influence of heredity becomes more and more powerful, causing the chance of the right variation being reproduced to become greater and greater.

Now with these three modifications the weight of the argument is entirely destroyed; for, allowing the Liptalis to produce only twenty offspring (a small number for a butterfly), the chances become even that one out of the twenty varies in the right direction. But nineteen out of the twenty, on the average, are soon killed off by the various causes that keep down the population of the species, and the chances are very much in favour of that one surviving which, by the hypothesis, has varied in the right direction. It is not pretended that this one would survive always, or even on the average, but in a large number of cases it would certainly do so; and taking Mr. Binnett's own estimate of a milion individuals as the population of a rare species, we may fairly estimate that in a quarter, or say even in a tenth part of these, the surviving offspring would possess the favourable variation. But now a new factor enters into the problem, of which Mr. Bennett takes no account. Those that have already varied tend to leave offspring varying in the same direction as themselves; and as these will all have an advantage, the offspring of the one-tenth will increase at the expense of those of the nine-tenths; and this tendency being still more powerful in the third generation, with the additional advantage as the numbers increase of the chance of both parents being favourable varieties, we may fairly expect the favourable to have completely exterminated the unfavourable variations, and to have firmly established themselves as a well-marked race. The enormous possible rapidity of multiplication, enabling a pair of individuals to produce millions in a few generations; the survival of the fittest, giving to favourable variationsnot their bare numerical chance, as Mr. Bennett supposes, but-a certainty in the long run of living at the expense of the rest; and the powerful influence of heredity, which actually increases the tendency to produce the favourable variations with each succeeding generation,-are three of the main foundation-stones of the theory of natural selection, yet all three are ignored in this attempted mathematical demonstration of its insufficiency.

There is one other point in the theory of the origin of "mimicry" that deserves notice. It is, that the modifications leading to it are much more easy to explain than 
those leading to new genera and families, because the changes effected are wholly superficial and are almost entirely confined to colour. Now colour is both more variable than any other character, and is less intimately correlated with structure, so that great changes of colour may rapidly occur without in any other way affecting the individual, as we see in almost all our domestic animals. Experiments in breeding show that very large spontaneous variations of colour are frequent in insects; and thus the number of steps to produce a required amount of change may be much fewer than in cases of structural modification, in which every other part of the organism has to be coordinated to work harmoniously with the modified organ.

I may here take the opportunity of denying that I have argued, as $\mathrm{Mr}$. Bennett says I have, that "an infinitesimal and inappreciable distinction may make the difference of a slightly longer span of life being allowed to the butterfly to lay its eggs in safety ;" and I cannot imagine how he could have imputed to me anything so absurd. What I have maintained is, that for natural selection to act, either in producing "mimicry," or structural changes, no large or special variations are required, because the usual amount of variabilaty which occurs in every part of every organism is sufficient. ("Contributions," pp. 287-29r.) But so far from supposing this to be "infinitesimal " or "inappreciable," I show that it is so palpable and so readily appreciated by horticulturists and breeders as to have enabled them to produce all the wonderful variety in our domestic animals and cullivated plants. And every entomologist know's that similar variability exists in insects, and that the constantly occurring variations of colour are especially great.

Mr. Bennett next returns to the laws of variation, and, because $\mathrm{Mr}$. Darwin says that we are profoundly ignorant of these (although he himself has done so much to eiucidate them), maintains that we cannot really know anything of the origin of species. As well miglst it be said that, because we are ignorant of the laws by which metals are produced and trees developed, we cannot know anything of the origin of steamships and railways. Spontaneou's "variations" are but the materials out of which "species" are formed, and we do not require to know how the former are produced in order to learn the origin of the latter. But though we may not know the laws which determine each variation in detail, the general causes which lead to variation are not difficult to perceive. We do not know all the laws and causes that have given their peculiar form to each mountain or each valley, but we know a good deal of the general causes which have produced them, and we can perceive that the reason no two are exactly alike is, the number and complexity of the causes and the enoless variety of conditions under which these causes have acted. In the far more complex operations of the development and growth of organisms, affected as we know they are by almost infinitely numerous and ever varying external and internal causes, it would be a much greater mystery if there were no variations, and if absolutely identical forms were produced by constant diversity of conditions. Even the succe sive offspring of the same parents are developed under very different conditions. At each succeeding year, and at every differcnt period of each year, the parents have changed in age, in size, in vigour, health, and constitution; they may be living in a different local.ty, have different food; and be subjected to very different pbysical and mental influences. Add to this the effect of cross unions of distinct individuals, each with its own characteristic peculiarities, which are in varying degrees transmitted to the offspring; and further, that these modified offspring are submitted to a somew hat different set of conditions from the parents, and intercross perhaps with a distinct set of individuals; and then add the effects of atavism in bringing up long lost ancestral characters, and it can hardly be said that the almost universal fact of "spontaneous variation" is quite unaccounted for. But, as I have already remarked, this variability could never by itself produce species, but must absolutely prevent their production without the eliminating, accumulating, and fixing powers of selection, multiplication, and heredity.

In Mr. Bennett's concluding passages he advances a theory of his own on the subject of "mimicry," to the effect that it is connected with intelligence or instinct, "and runs almost pari passu with the development of the nervous system" In support of this view he asserts that it is "strongly developed in birds." This is erroneous. In birds it is very rare, only two or three cases being known, and these not nearly so remarkable as hundreds that occur in insects; and in mammalia, with the exception of one doubtful case, it is absolutely unknown. This view, therefore, is directly opposed by the facts.

I have only one more point to notice, a charge of inconsistency against myself. Mr. Bennett quotes me to the effect that man's chief peculiarities of form and structure were developed before his intellect had raised him above the condition of the brutes, and also imputes to me the belief that certain peculiarities in his structure (the absence of hair on his body, for example) "must have been in some way connected with his reasoning powers." But this is Dr. Laycock's view, which I have expressly repudiated, and I have never used a word to show that I believed that man has modified his own structure in any important degree, by the conscious or unconsc:ous exercise of his reasoning powers. I have, it is true, declared my belief that "some intelligence" has acted on him, but I have also, I think, made it quite clear that I did not believe it to be his own intelligence. The inconsistency, therefore, is of Mr. Bennett's making.

I think I have now noticed the chief points in this last assault on the theory of Natural Selection, which has failed, like all preceding ones. Its author also exhibits the usual inability to keep steadily before him the great fundamental principles of the theory he is discussing, so that his arguments continually break down owing to his taking a partial and wholly inadequate view of its mode of operation. In the case of "mimicry" he is not sufficiently careful in his statement of the facts, and this, combined with his imperfect grasp of the theory, entirely neutralises the elaborate numerical proofs which at first sight appear so overwhelming. ALFRED R. WALLACE

\section{SCIENCE IN PARTS}

I $N$ the course of an article on the present condition of Paris, the Engineer gives the following account of the effects of the war. The use of the electric light is common to both sides in the present struggle, but the French have used it largely. The apparatus set up on Montmartre is arranged by M. Bazin, and is electromiannetic. The central cylinder supports four series of double coils covered with copper wire enveloped in silk; the cylinder is rotated by a small steam-engine of 3 -horse power, making 400 revoutions per minute. The lamp used is of the ordinary form, with the Foucault-Dubosc resulator. The reflector is parabolic in form, and the whole is surrounded by a shield to hide it from the enemy. This light, from its elevated position, commands the whole of Paris and the plains around A spectator on Montmartre sees distinctly the details of the façade of a building which stands 2,600 metres off; at 2,900 metres a man may be seen standing at a window, at 3,000 metres a mass of cavalry or infantry is distinguishable, and at 4,000 metres the dome of the Invalides, with its bands of gold, is brilliant. A man cannot be seen on the dome at that distance, but on walking towaris the building all soon becomes clear. On the ramparts, at 3,800 metres from Montmartre, the light is sufficient to read an ordinary newspaper. 